\section{Postharvest Quality of Dragon Fruit (Hylocereus spp.) after X-ray Irradiation Quarantine Treatment}

\author{
Marisa M. Wall ${ }^{1}$ \\ U.S. Department of Agriculture, Agricultural Research Service, U.S. Pacific \\ Basin Agricultural Research Center, P.O. Box 4459, Hilo, HI 96720-0459
}

\author{
Shakil A. Khan \\ Insect Biotechnology Division, Institute of Food and Radiation Biology, Atomic \\ Energy Research Establishment, Bangladesh Atomic Energy Commission, \\ GPO Box 3787, Dhaka 1000, Bangladesh
}

Additional index words. disinfestation, pitaya, tropical fruit

\begin{abstract}
The quality of three dragon fruit clones (Hylocereus spp.) was determined after $\mathrm{x}$-ray irradiation for disinfestation of quarantine pests. Fruit were treated with irradiation doses of $0,200,400,600$, or $800 \mathrm{~Gy}$ and stored for 12 days at $10^{\circ} \mathrm{C}$. Irradiation did not affect soluble solids content, titratable acidity, or fructose concentrations. Glucose, sucrose, and total sugar concentrations decreased linearly as dose increased. Minimal softening occurred in the outer flesh layers for fruit treated with 400 or $600 \mathrm{~Gy}$ irradiation. Surface color, peel injury, and bract appearance differed among the three clones with irradiation stress, but in all cases, visible changes were minor. Fruit decay was absent or minimal, and disease ratings were not affected by irradiation. Irradiation treatment of dragon fruit at doses 800 Gy or less would ensure visual and compositional quality while providing quarantine security.
\end{abstract}

Dragon fruit is an exotic tropical fruit produced by epiphytic, night-blooming Hylocereus cacti of neotropical origin. Also known as pitaya, pitahaya, strawberry pear, and thang loy, the fruit are oblong-oval with bright red skin covered with green bracts or "scales," accounting for the name dragon fruit (Morton, 1987; Paull, 2004). The flesh is sweet, delicate, white or red-purple, and contains numerous tiny black seeds. The fruit is nonclimacteric and has the best flavor when harvested at full red color (Nerd et al., 1999).

Dragon fruit is being grown commercially in Israel, Vietnam, Taiwan, Nicaragua, Australia, and the United States (Merten, 2003). Two species (H. undatus and H. polyrhizus) and their hybrids comprise most of the production. Dragon fruit is enjoyed as a fresh fruit or juice, but also is valued as a natural food colorant. The red peel of both species as well as the red-purple flesh of $H$. polyrhizus contain water-soluble betacyanin pigments similar to those found in red beets (Beta vulgaris) (Wybraniec and Mizrahi, 2002).

\footnotetext{
Received for publication 20 June 2008. Accepted for publication 19 Aug. 2008.

Mention of a trademark, warranty, proprietary product, or vendor does not constitute a guarantee by the U.S. Department of Agriculture and does not imply its approval to the exclusion of other products or vendors that may be suitable.

We thank Eric Weinert for contributing irradiation services and Suzanne Sanxter, Sandra Silva, and Alba Enrique de Briano for excellent technical assistance.

${ }^{1}$ To whom reprint requests should be addressed; e-mail marisa.wall@ars.usda.gov
}

In Hawaii, dragon fruit is a new specialty fruit crop grown for local consumption but has potential to supply U.S. mainland markets. However, dragon fruit is a host for tephritid fruit flies and therefore subject to quarantine restrictions. Hot forced air treatments have been proposed for dragon fruit disinfestation with minimal reduction in quality (Hoa et al., 2006); however, irradiation generally is more efficient and less phytotoxic than heat treatments for tropical fruit (Follett and Sanxter, 2000, 2002, 2003). Irradiation may be the most widely tolerated of all the major phytosanitary treatments, especially at the low doses required for quarantine security against fruit flies and many other pests (Hallman, 2001). The USDA's Animal Plant Health Inspection Service (APHIS) allows export of dragon fruit from Hawaii after irradiation with a 400-Gy dose or after irradiation with a $150-\mathrm{Gy}$ dose and inspection for mealybugs (Dysmicoccus neobrevipes, Maconellicoccus hirsutus, and Pseudococcus cryptus) (APHIS, 2008). The island of Hawaii has a commercial electron beam facility that is used for quarantine treatment of tropical fruits. Local growers are interested in exporting irradiated dragon fruit from Hawaii, but quality and sensory analyses are needed before markets can be developed and large shipments can be risked.

Dose uniformity ratios at the commercial electron beam facility in Hawaii (designed to treat fresh produce) are typically 1.5 to 2.0 (Follett et al., 2007). Therefore, commodities treated with a minimum absorbed dose of 400 Gy may receive maximum doses of 600 to
800 Gy irradiation, which may approach or exceed fruit tolerance limits. Dragon fruit injury must be absent or minimal before irradiation treatment can be used commercially. There are no published reports of dragon fruit radiotolerance limits. Therefore, the objectives of this study were to determine the quality of dragon fruit exposed to irradiation doses 800 Gy or less.

\section{Materials and Methods}

Fruit harvest. Two dragon fruit (Hylocereus spp.) clones were harvested 35 to $40 \mathrm{~d}$ after anthesis (DAA) on 13 and 20 Sept. 2007 from a commercial orchard in the South Kona district of Hawaii island. Clone 1 (H. undatus $\times H$. polyrhizus $)$ has red skin with red-purple flesh and clone 2 (H. undatus) has red skin with white flesh. Clone 3 (H. undatus), with red skin and white flesh, was harvested 45 to 50 DAA on 11 Oct. 2007 from a commercial orchard in the Puna district.

Irradiation treatment. Fruit from a single clone were packed in microperforated polypropylene bags (Elkay Plastics, Los Angeles, CA) and placed inside fiberboard boxes $(36 \times$ $25 \times 15 \mathrm{~cm}$ ) with eight to 12 fruit per box. Four dosimeters (Opti-chromic detectors, FWT-70-83M; Far West Technology, Goleta, CA) were placed inside each box in the areas where maximum and minimum absorbed doses were measured during extensive dose mapping. After irradiation, the dosimeters were read at $600 \mathrm{~nm}$ with a FWT-200 reader (Far West Technology) to determine the dose variation within each box. The irradiation was carried out at a commercial irradiation facility on the island of Hawaii (CW Hawaii Pride LLC, Keaau, HI). The facility uses an electron linear accelerator $(5 \mathrm{MeV}$, model TB-5/15; L-3 Communication Titan Corp., San Diego, CA) and converts the electron beam into $\mathrm{x}$-rays for treatment of produce. Dragon fruit were treated with target absorbed doses of $0,200,400,600$, and 800 Gy radiation. Each radiation dose was replicated four times for each experiment. The average minimum and maximum absorbed doses inside the boxes were 188 to 204,386 to 414,590 to 639 , and 792 to 839 Gy with corresponding dose uniformity ratios of 1.09 , $1.07,1.08$, and 1.06 for the 200-, 400-, 600-, and $800-$ Gy target dose treatments, respectively. After treatment, the fruit were stored at $10^{\circ} \mathrm{C}$ for $12 \mathrm{~d}$. Control treatments ( $\left.0 \mathrm{~Gy}\right)$ were not subjected to irradiation but were otherwise handled the same as the treated fruit.

Quality analyses. Surface color measurements were taken at three positions externally and internally per fruit with a chromameter (model CR-300; Minolta Corp., Ramsey, NJ) and recorded as lightness $\left(\mathrm{L}^{*}\right)$, chroma $\left(\mathrm{C}^{*}\right)$, and hue angle $\left(\mathrm{h}^{\circ}\right)$ under standard illuminant C. Peel injury (scald) was assessed visually and rated as the percentage of the surface area with grayish discoloration, in which $0=0 \%$, $1=1 \%$ to $20 \%, 2=21 \%$ to $40 \%, 3=41 \%$ to $60 \%, 4=61 \%$ to $80 \%$, and $5=81 \%$ to $100 \%$. 
Visual ratings for bract appearance and the presence of fruit rots were according to the methods of Hoa et al. (2006). Bract appearance was assessed visually on a 0 to 5 scale, in which $0=$ bright color with no browning or blackening, 3 = yellowing and browning of margins, and $5=$ bracts completely blackened and desiccated. Blossom-end and body rots were rated on a 0 to 3 scale, in which $0=$ no disease, $1=5 \%$ to $10 \%$ of the surface area diseased, $2=16 \%$ to $25 \%$ of the surface area diseased, and $3=$ greater than $50 \%$ of the surface area diseased. For blossom-end rots, only the area around the floral (distal) end of the fruit was rated.

External and internal flesh firmness was measured using a force gauge (Ametek, Largo, FL) having a 6-mm diameter flathead probe and mounted on a motorized test stand. External measurements were taken at two locations around the middle of the fruit by peeling back a flap of the skin. Fruit were cut equatorially, and internal measurements were taken at two locations from one of the horizontal halves. Peak force $(\mathrm{N})$ was measured at a penetration depth of $3 \mathrm{~mm}$.

For soluble solids measurement, a composite sample was created from the fruits and a 10-g sample of pulp was homogenized and the liquid was measured with a hand refractometer measuring \% Brix (Atago, Kirkland, WA). Titratable acidity was measured from a 5-g homogenized, filtered pulp obtained from the composite fruit samples. Acidity was determined by titrating to a final $\mathrm{pH}$ of 8.1 with $0.01 \mathrm{~N} \mathrm{NaOH}$ and calculated as citric acid equivalents.

Sugar analysis. For sugar determinations, pulp (10 g) from the fruit composites was combined in a test tube and homogenized in $50 \mathrm{~mL} 80 \%$ ethanol for $1 \mathrm{~min}$ at high speed. The slurry was immediately boiled for 15 min, cooled, and filtered. The sugar extract was brought to a final volume of $100 \mathrm{~mL}$ with $80 \%$ ethanol. An aliquot of the extract was filtered through a $0.22-\mu \mathrm{m}$ membrane filter into vials for high-pressure liquid chromatography (HPLC).

HPLC was used to separate and quantify glucose, fructose, and sucrose in the dragon fruit samples. Sugars were analyzed by injecting $20 \mu \mathrm{L}$ of sample into an Agilent 1100 series liquid chromatograph (Agilent Technologies, Wilmington, DE) with HPLCgrade acetonitrile:water $(3: 1)$ as the mobile phase and a Zorbax carbohydrate column (amino-propylsilane; $4.6 \mathrm{~mm} \times 150 \mathrm{~mm}, 5$ $\mu \mathrm{m})$ as the stationary phase followed by a refractive index detector. The flow rate was $1.4 \mathrm{~mL} / \mathrm{min}$; the temperatures were $4{ }^{\circ} \mathrm{C}$ for the autosampler and $30{ }^{\circ} \mathrm{C}$ for the column compartment. Sucrose, glucose, and fructose peaks of the samples were identified according to HPLC retention times in comparison with authentic standards. For recovery tests, samples were spiked with standard solutions before extraction. The detection limit was $2 \mu \mathrm{g}$.

Statistical analyses. Data were subjected to analysis of variance using the general linear models procedure (SAS Institute, 1999) for a randomized complete block design with four blocks for each experiment (Kona fruit and Puna fruit). Dose-response was tested by orthogonal polynomial analysis in SAS. Where applicable, means were separated using the Waller-Duncan k-ratio $t$ test. Data for each experiment were analyzed separately. After checking for homogeneity of variance, a combined analysis was completed for those variables in which differences between experiments (harvest location) and interactions were not significant.

\section{Results and Discussion} Puna districts had similar $(P>0.05)$ irradiation responses for percent weight loss, fruit firmness, and sugar concentrations; therefore, data for Kona and Puna experiments were combined for these variables. Overall fruit weight loss was low $(0.8 \%$ to $1.5 \%)$, but
Dragon fruit harvested from the Kona and

dragon fruit treated with 600 or 800 Gy radiation lost slightly more weight than control fruit after $12 \mathrm{~d}$ storage at $10{ }^{\circ} \mathrm{C}$ (Fig. 1B). In comparison, Nerd et al. (1999) reported water loss of $4.4 \%$ for nontreated dragon fruit stored $14 \mathrm{~d}$ at $14{ }^{\circ} \mathrm{C}$. As radiation dose increased, flesh firmness increased linearly $(P<0.0001)$, whereas external firmness decreased in a quadratic trend $(P=$ 0.007 ) (Fig. 1A). Therefore, only minimal softening occurred in the outer flesh layers for fruit treated with 400 or 600 Gy radiation. However, softening can limit shelf life, and further studies are needed to determine the maximum shelf life of irradiated dragon fruit. Other nonclimacteric fruits had minimal (blueberries) to substantial (cherries, oranges, rambutans) softening at doses 1000 Gy or less. (Boylston et al., 2002; Drake and Neven, 1997; Ladaniya et al., 2003; Miller et al., 1994).
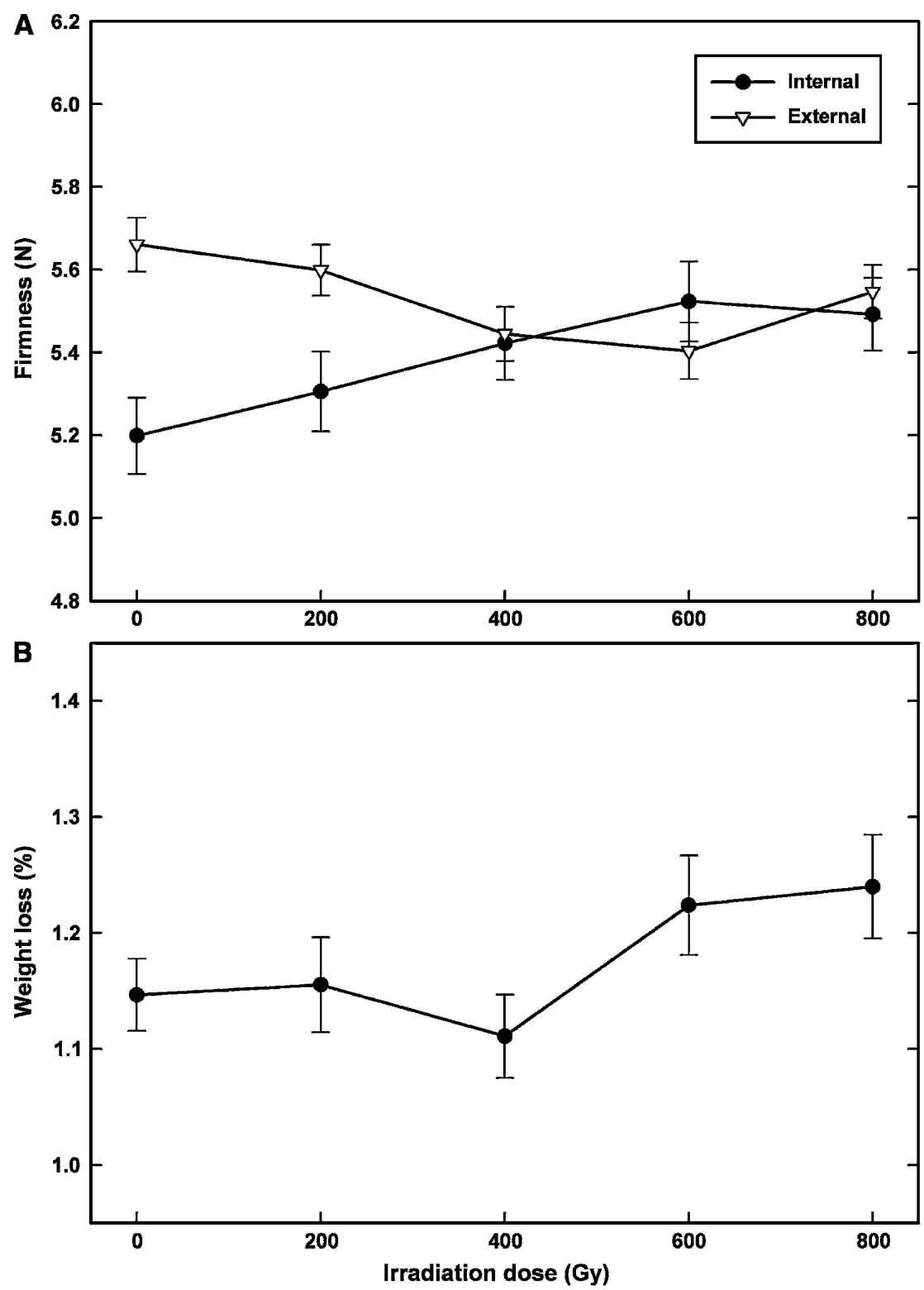

Fig. 1. Firmness (A) and weight loss (B) of dragon fruit exposed to 0, 200, 400, 600, or 800 Gy irradiation and stored at $10{ }^{\circ} \mathrm{C}$ for $12 \mathrm{~d}$. Data were combined for clones harvested from the Kona and Puna districts. 
Sugars in the dragon fruit clones were primarily glucose $\left(60\right.$ to $\left.65 \mathrm{mg} \cdot \mathrm{g}^{-1}\right)$ and fructose (28 to $\left.40 \mathrm{mg} \cdot \mathrm{g}^{-1}\right)$ with lesser amounts of sucrose ( 1.8 to $2.5 \mathrm{mg} \cdot \mathrm{g}^{-1}$ ) (Fig. 2 ). Sucrose comprised $\approx 2 \%$ of the total sugar content. Total sugar concentrations ranged from $101 \mathrm{mg} \cdot \mathrm{g}$ for nonirradiated fruit to $89 \mathrm{mg} \cdot \mathrm{g}^{-1}$ for those treated with $800 \mathrm{~Gy}$ (data not shown). Esquival et al. (2007) also found glucose and fructose as predominant sugars in several Hylocereus genotypes with sucrose accounting for less than $1 \%$ of the total sugar content. Nerd et al. (1999) reported total sugar concentrations of 80 to $90 \mathrm{mg} \cdot \mathrm{g}^{-1}$ at full color.

Fructose concentrations were not affected by radiation dose $(P=0.36)$, but glucose and sucrose decreased linearly as dose increased to 800 Gy $(P=0.01$ and $P<0.001$, respec-
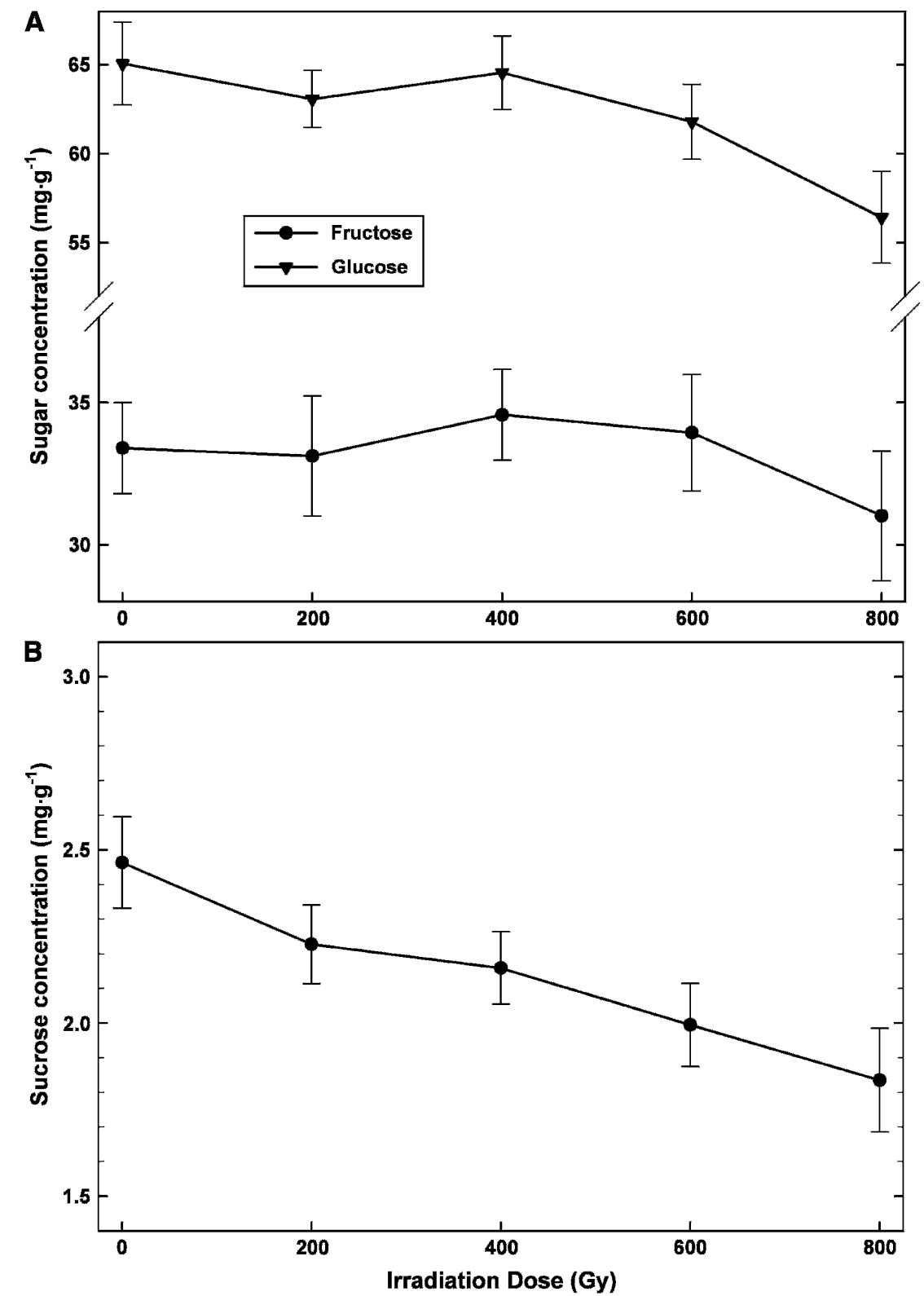

Fig. 2. Fructose, glucose (A), and sucrose (B) concentrations for dragon fruit exposed to $0,200,400,600$, or 800 Gy irradiation and stored at $10^{\circ} \mathrm{C}$ for $12 \mathrm{~d}$. Data were combined for clones harvested from the Kona and Puna districts. tively) (Fig. 2). Irradiation may indirectly alter carbohydrate metabolism by increasing respiration to meet the energy needs of cells damaged by free radicals generated during treatment (Thomas, 2001). For dragon fruit, these changes in sugars were apparently for other fruit crops. Irradiation either had no effect or caused a slight decrease in total sugars for apples, pears, papayas, mangoes, lychees, and strawberries (Beyers et al., 1979; Drake et al., 2003; Mitchell et al., 1992; Morris and Jessup, 1994). However, organoleptic evaluations are needed to determine whether changes in sugar concentrations impact the flavor of irradiated dragon fruit.

Total soluble solids (TSS) $(P=0.71)$ and titratable acidity (TA) $(P=0.62)$ were not minor and followed a similar pattern reported affected by radiation dose for any of the clones. However, overall means for the three dragon fruit clones were different $(P \leq 0.05)$. TSS averaged $12.8 \%, 12.3 \%$, and $12 \%$, and TA was $0.24 \%, 0.18 \%$, and $0.10 \%$ for clones 1,2 , and 3, respectively. Clone 3 fruit (grown in Puna) were harvested at a later maturity stage (45 to 50 DAA) than the Kona fruit (35 DAA) and would be expected to have higher soluble solids (To et al., 2000). However, the Puna district has a wetter climate (average rainfall, $355 \mathrm{~cm} /$ year) than the Kona district (190 cm/year), accounting for slightly lower soluble solids and acidity in Puna-grown fruit. Cultivated dragon fruit typically are harvested when the skin color approaches or reaches full red (Nerd et al., 1999). Harvest time differs among production regions with recommendations for 28 to $32 \mathrm{DAA}$ in Vietnam (Hoa et al., 2006; To et al., 2000), 32 to 35 DAA in Israel (Nerd et al., 1999), 40 to 45 DAA in California (Merten, 2003), and 35 to 50 DAA in Hawaii (Zee et al., 2004).

Others have reported TSS of $9 \%$ to $15 \%$ for $H$. undatus and $8 \%$ to $11 \%$ for $H$. polyrhizus (Esquival et al., 2007; Hoa et al., 2006; Nerd et al., 1999; Stintzing et al., 2003; To et al., 2000; Vaillant et al., 2005). TSS was $12.2 \%$ after 2 weeks storage at $14{ }^{\circ} \mathrm{C}$ (Nerd et al., 1999). TA values ranged from $0.32 \%$ to $0.69 \%$ at full color for Hylocereus genotypes grown in Costa Rica (Esquival et al., 2007), whereas Nerd et al. (1999) reported 0.22\% TA for $H$. undatus fruit at full color, similar to our results for clones 1 and 2 .

Surface color, peel injury, bract appearance, and disease ratings differed among the three clones with irradiation stress $(P \leq$ 0.05). Clone 1 (red peel and red-purple flesh type) showed minor changes in external color after irradiation (Table 1). The peel remained red but was lighter and brighter in color for irradiated fruits. Clone 1 fruit also maintained a vivid, red-purple flesh color after irradiation and storage. Clones 2 and 3 (red peel and white flesh types) had duller red peel color and grayish (clone 2) or yellowish (clone 3) flesh color after irradiation at the highest doses. In all cases, visible color changes were minor.

Slight peel injury was observed for clones 1 and 2 after 800 Gy radiation (Table 1). This irradiation scald appeared as diffuse darkening of the peel surface but was barely perceptible. For over 500 fruit evaluated, only four fruit had a peel injury rating of 2 . Nevertheless, the possibility of irradiation scald at 800 Gy underscores the need for uniform application of the minimum effective quarantine dose during commercial treatment of dragon fruit. Many other fruits such as apples, bananas, pears, and rambutans also reach a phytotoxic threshold in the 750- to 1000-Gy dose range (Boylston et al., 2002; Drake et al., 1999; Fan and Mattheis, 2001; Wall, 2007), but cultivar, preharvest conditions, fruit maturity, and storage conditions can mediate phytotoxicity (Morris and Jessup, 1994).

Irradiation treatment can either advance or reduce postharvest disorders in treated 
Table 1. Surface color and peel injury of dragon fruit after irradiation treatments and storage at $10{ }^{\circ} \mathrm{C}$ for $12 \mathrm{~d}$.

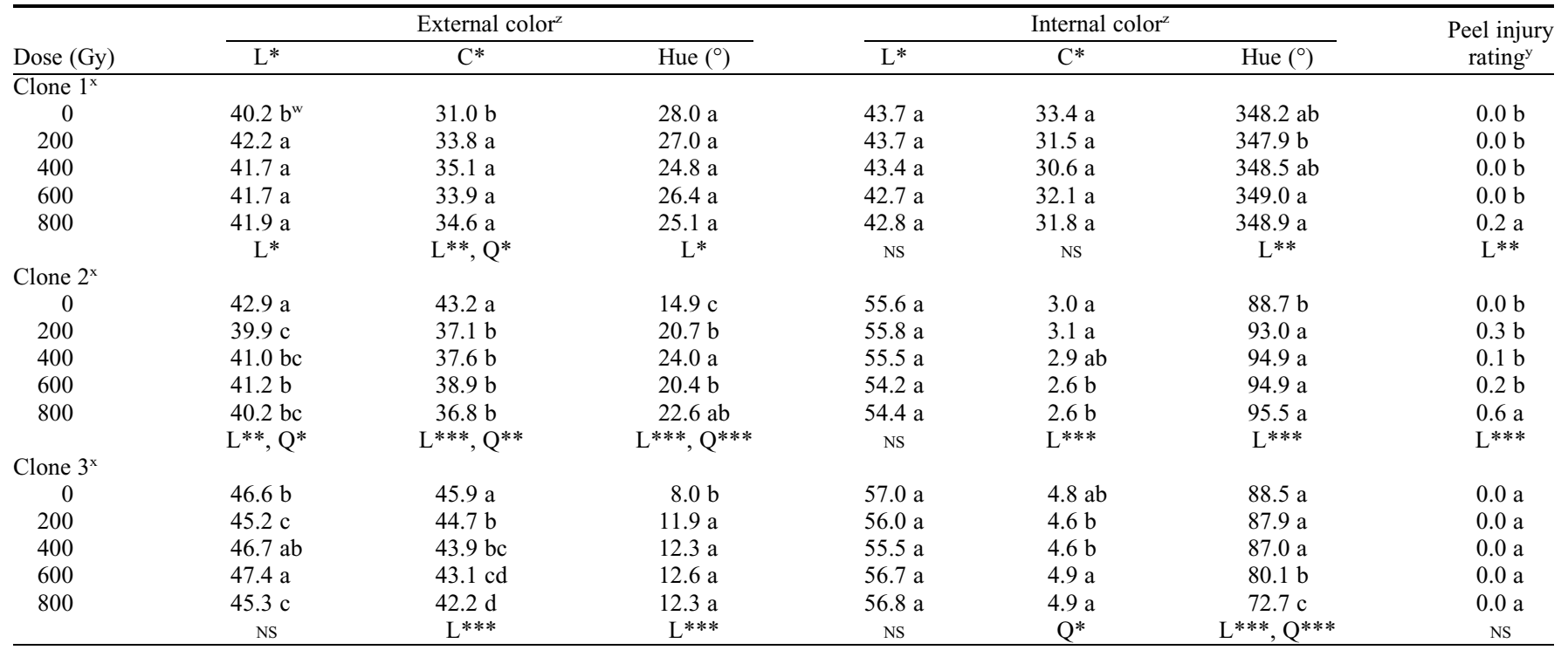

${ }^{2} \mathrm{Lightness}\left(\mathrm{L}^{*}\right)$ is on a scale of 0 to 100 . Chroma $(\mathrm{C})$ is on a scale of 0 to 60 , with full saturation at 60 . Hue angle of $0^{\circ}\left(360^{\circ}\right)=$ red, $90^{\circ}=\mathrm{yellow}, 180^{\circ}=$ green, and $270^{\circ}=$ blue. Values are means of 36 to 48 observations.

yPeel injury (scald) was assessed visually and rated as the percentage of the surface area showing gray-brown discoloration, in which $0=0 \%, 1=20 \%, 2=21 \%$ to $40 \%, 3=41 \%$ to $60 \%, 4=61 \%$ to $80 \%$, and $5=81 \%$ to $100 \%$. Values are means of 36 to 48 observations.

${ }^{\mathrm{x}}$ Clone 1 had red peel and red-purple flesh; clones 2 and 3 had red peel and white flesh. Clones 1 and 2 were harvested from the Kona district. Clone 3 was harvested from the Puna district.

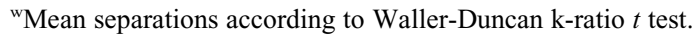

Ns,", **, **** Nonsignificant or significant at $P \leq 0.05,0.01$ or 0.001 , respectively. Significant dose response trends were linear (L) or quadratic (Q).

fruit, depending on dose (Morris and Jessup, 1994). For dragon fruit, this could include bract wilting and browning, softening, or decay. However, in our experiments, clones 1 and 2 showed no irradiation effect on bract appearance $(P>0.05)$, and clone 3 showed the greatest bract senescence on the nonirradiated fruit (Fig. 3A). Also, fruit decay was absent or minimal, and disease ratings were not affected by irradiation $(P>0.05)$ (Fig. 3B). However, $\approx 12 \%$ of clone 3 fruit had minor disease symptoms (data not shown), and this could be attributed to a later harvest date or wetter production climate for the Puna-grown dragon fruit. Conversely, $1 \%$ of Kona-grown fruit (clones 1 and 2) developed postharvest disease symptoms.

Irradiation is generally less phytotoxic than thermal, cold, or fumigation treatments (Follett and Sanxter, 2000, 2002, 2003; Moy and Wong, 2002). Also, generic irradiation doses can be developed to target a broad group of pests, regardless of host crop (Follett et al., 2007). For dragon fruit, research on disinfecting hot air treatments showed that fruit were heat-tolerant at $46.5^{\circ} \mathrm{C}$ for $20 \mathrm{~min}$, but quality declined at higher temperatures and durations (48.5 ${ }^{\circ} \mathrm{C}, 70$ to $90 \mathrm{~min}$ ) (Hoa et al., 2006). Although not compared directly, dragon fruit are likely to be more radiotolerant than thermal-tolerant, and irradiation could become the preferred quarantine treatment where facilities are available at feasible costs.

\section{Conclusions}

The limits of radiotolerance were established for dragon fruit, a high-value, exotic tropical fruit. The results will support rapid adoption of the final rule issued by APHIS (2008) allowing interstate movement of dragon fruit from Hawaii after irradiation treatment. Posttreatment inspection is not required in Hawaii if the fruit receives 400 Gy radiation, whereas at the lower approved dose (150 Gy), dragon fruit must be inspected for the presence of mealybugs and have the sepals removed (APHIS, 2008). The recommended storage temperature for dragon fruit is $10^{\circ} \mathrm{C}$ for a maximum of $14 \mathrm{~d}$ (Paull, 2004). Irradiated fruit retained visual and compositional quality under these conditions $\left(10^{\circ} \mathrm{C}\right.$ for $12 \mathrm{~d}$ ), which would be sufficient for air transport from Hawaii to U.S. mainland markets. Exporters using irradiation for quarantine security can develop markets for dragon fruit with confidence that quality will not be compromised by doses $800 \mathrm{~Gy}$ or less.

\section{Literature Cited}

Animal and Plant Health Inspection Service (APHIS), U.S. Department of Agriculture. 2008. Interstate movement of fruit from Hawaii. Final rule. Fed. Regist. 73:2485124856.

Beyers, M., A.C. Thomas, and A.J. van Tonder. 1979. Gamma-irradiation of subtropical fruits. I. Compositional tables of mango, papaya, strawberry, and litchi fruits at edible-ripe stage. J. Agr. Food Chem. 27:37-42.

Boylston, T.D., C.A. Reitmeier, J.H. Moy, G.A. Mosher, and L. Taladriz. 2002. Sensory quality and nutrient composition of three Hawaiian fruits treated by x-irradiation. J. Food Qual. 25:419-433.

Drake, S.R. and L.G. Neven. 1997. Quality response of 'Bing' and 'Rainier' sweet cherries to low dose electron beam irradiation. J. Food Processing Preserv. 21:345-351.

Drake, S.R., L.G. Neven, and P.G. Sanderson. 2003. Carbohydrate concentrations of apples and pears as influenced by irradiation as a quarantine treatment. J. Food Processing Preserv. 27:165-172.

Drake, S.R., P.G. Sanderson, and L.G. Neven. 1999. Response of apple and winter pear fruit quality to irradiation as a quarantine treatment. J. Food Processing Preserv. 23:203-216.

Esquival, P., F.C. Stintzing, and R. Carle. 2007. Comparison of morphological and chemical fruit traits from different pitaya genotypes (Hylocereus sp.) grown in Costa Rica. J. Applied Botany Food Quality 81:7-14.

Fan, X. and J.P. Mattheis. 2001. 1-Methylcyclopropene and storage temperature influence responses of 'Gala' apple fruit to gamma irradiation. Postharvest Biol. Technol. 23: 143-151.

Follett, P.A. and S.S. Sanxter. 2000. Comparison of rambutan quality after hot forced-air and irradiation quarantine treatments. HortScience 35:1315-1318.

Follett, P.A. and S.S. Sanxter. 2002. Longan quality after hot-water immersion and $\mathrm{x}$-ray irradiation quarantine treatments. HortScience 37:571-574.

Follett, P.A. and S.S. Sanxter. 2003. Lychee quality after hot-water immersion and $\mathrm{x}$-ray irradiation quarantine treatments. HortScience 38:11591162.

Follett, P.A., M. Yang, K. Lu, and T. Chen. 2007. Irradiation for postharvest control of quarantine insects. Formosan Entomology 27:1-15.

Hallman, G.J. 2001. Irradiation as a quarantine treatment, p. 113-130. In: Molins, R.A. (ed.). Food irradiation: Principles and applications. John Wiley and Sons, Inc., New York, NY.

Hoa, T.T., C.J. Clark, B.C. Waddell, and A.D. Woolf. 2006. Postharvest quality of dragon fruit (Hylocereus undatus) following disinfesting 

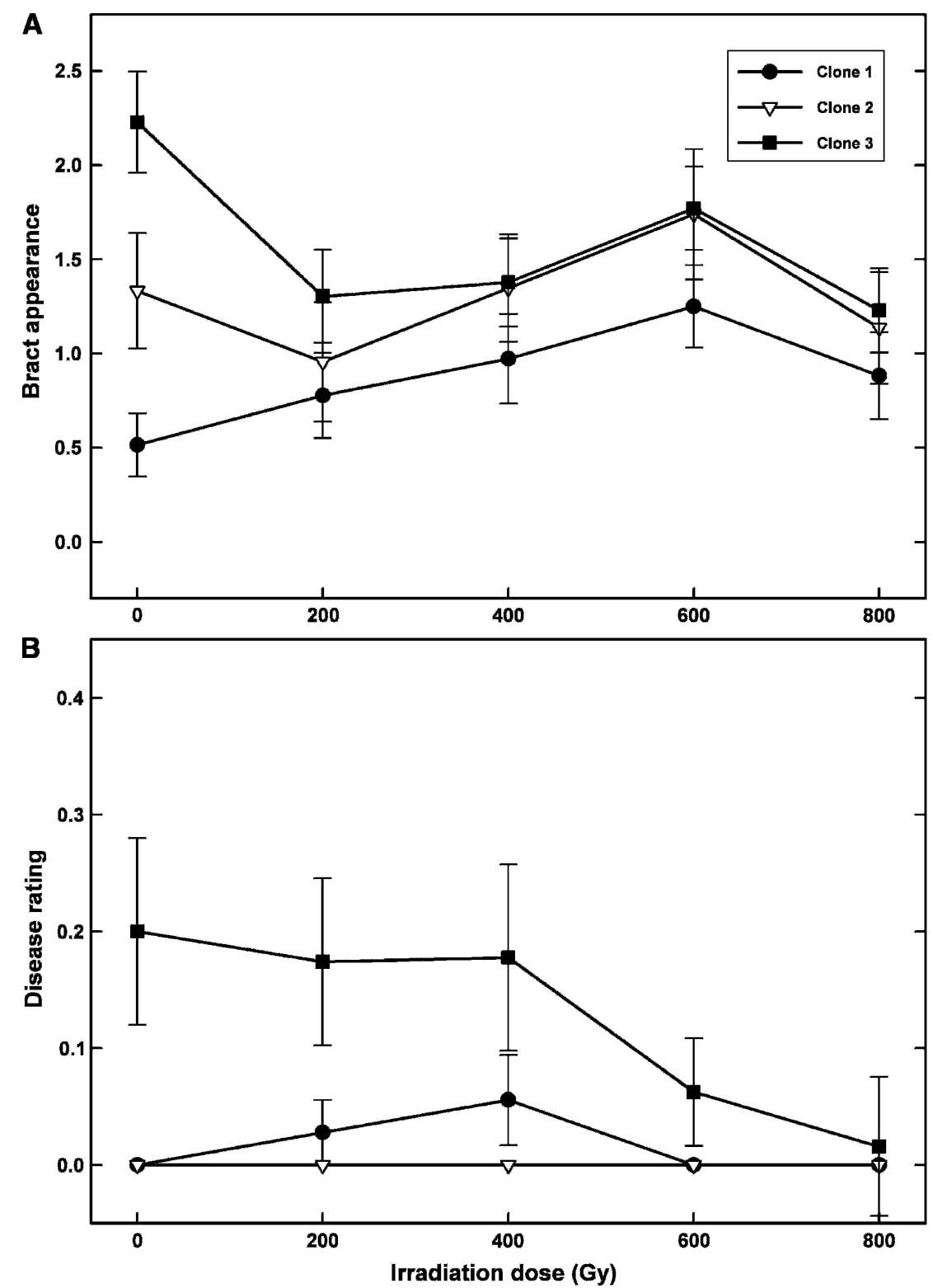

Fig. 3. Bract appearance (A) and disease ratings (B) for three dragon fruit clones exposed to 0, 200, 400, 600 , or $800 \mathrm{~Gy}$ irradiation and stored at $10^{\circ} \mathrm{C}$ for $12 \mathrm{~d}$.

hot air treatments. Postharvest Biol. Technol. 41:62-69.

Ladaniya, M.S., S. Singh, and A.K. Wadhawan. 2003. Response of 'Nagpur' mandarin, 'Mosambi' sweet orange and 'Kagzi' acid lime
Miller, W.R., R.E. McDonald, T.G. McCollum, and B.J. Smittle. 1994. Quality of 'Climax' blueberries after low dosage electron beam irradiation. J. Food Qual. 17:71-79.

Mitchell, G.E., R.L. McLauchlan, A.R. Isaacs, D.J Williams, and S.M. Nottingham. 1992. Effect of low dose irradiation on composition of tropical fruits and vegetables. J. Food Comp. Anal. 5:291-311.

Morris, S.C. and A.J. Jessup. 1994. Irradiation, p. 163-190. In: Paull, R.E. and J.W. Armstrong (eds.). Insect pests and fresh horticultural products: Treatments and responses. CAB Internl., Wallingford, UK.

Morton, J. 1987. Cactacea, strawberry pear, p. $347-$ 348. In: Dowling, C.F. (ed.). Fruits of warm climates. J.F. Morton, Miami, FL.

Moy, J.H. and L. Wong. 2002. The efficacy and progress in using radiation as a quarantine treatment of tropical fruits-A case study in Hawaii. Radiat. Phys. Chem. 63:397401.

Nerd, A., F. Gutman, and Y. Mizrahi. 1999. Ripening and postharvest behaviour of fruits of two Hylocereus species (Cactaceae). Postharvest Biol. Technol. 17:39-45.

Paull, R.E. 2004. Dragon fruit. In: Gross, K.C., C.Y. Wang, and M. Salveit (eds.). The commercial storage of fruits, vegetables and florist and nursery stocks. USDA, ARS Agricultural Handbook \#66. 11 Feb. 2008. <http://usna. usda.gov/hb66/contents.html>.

SAS Institute. 1999. SAS system for Windows, version 8 . SAS Inst., Cary, NC.

Stintzing, F., A. Schieber, and R. Carle. 2003. Evaluation of colour properties and chemical quality parameters of cactus juice. Eur. Food Res. Technol. 216:303-311.

Thomas, P. 2001. Irradiation of fruits and vegetables, p. 213-240. In: Molins, R.A. (ed.). Food irradiation: Principles and applications. John Wiley and Sons, Inc., New York, NY.

To, L.V., N. Ngu, N.D. Duc, D.T.K. Trinh, N.C. Thanh, D.V.H. Mien, C.N. Hai, and T.N. Long 2000. Quality assurance system for dragon fruit. ACIAR Proc. 100:101-114.

Vaillant, F., A. Perez, I. Davila, M. Dornier, and M. Reynes. 2005. Colorant and antioxidant properties of red-purple pitahaya (Hylocereus sp.). Fruits 60:3-12.

Wall, M.M. 2007. Postharvest quality and ripening of Dwarf Brazilian bananas (Musa sp.) after $\mathrm{x}$-ray irradiation quarantine treatment. HortScience 42:130-134.

Wybraniec, S. and Y. Mizrahi. 2002. Fruit flesh betacyanin pigments in Hylocereus cacti. J. Agr. Food Chem. 50:6086-6089.

Zee, F., C. Yen, and M. Nishina. 2004. Pitaya. Univ. Hawaii Coop. Ext. Serv. F\&N-9. 